\title{
Assessment of cochlear implantation outcome in patients with enlarged vestibular aqueduct syndrome
}

\author{
Ossama A. Sobhy ${ }^{\mathrm{a}}$, Mohamed B. Attallah ${ }^{\mathrm{a}}$, Rania M. Abdou ${ }^{\mathrm{a}}$, \\ Amira M. Al-Mahy ${ }^{b}$
}

\author{
aDepartment of Otolaryngology, Alexandria \\ University School of Medicine, Alexandria \\ University Hospitals, ${ }^{b}$ Department of \\ Otolaryngology, Students Hospital, Health \\ Insurance Organization, Alexandria, Egypt \\ Correspondence to Amira M. Al-Mahy, Master \\ of Audiology, MSc, Students Hospital, Health \\ Insurance Organization, Sporting Abu-Keer \\ Avenue, Alexandria, Egypt. Tel: +20 122447 \\ 1451 ; \\ e-mail: amira.mahy@gmail.com \\ Received 3 June 2018 \\ Accepted 6 August 2018
}

The Egyptian Journal of Otolaryngology 2018, 34:316-325

\begin{abstract}
Context
Theoverall outcome of cochlear implantation $(\mathrm{Cl})$ in patients with enlarged vestibular aqueduct (EVA) was comparable to other $\mathrm{Cl}$ users. However, there were various concerns regarding surgical issues that may affect postoperative outcome. Moreover, exact timing for $\mathrm{Cl}$ is still a matter of debate owing to the fluctuating nature of the disorder.

Aim

This study aimed to investigate speech and language outcome in patients with EVA who had undergone $\mathrm{Cl}$.

Patients and methods

This prospective study included 48 participants who underwent $\mathrm{Cl}$. The participants' age ranged from 4 to 28 years. The participants were divided according to preoperative radiological studies of petrous temporal bone into isolated EVA, EVA-IPII (incomplete partition type II), and control groups. Patients' records were revised for preoperative investigations as well as available intraoperative data. Aided hearing thresholds, auditory skills, and aided speech perception abilities were all assessed postoperatively in all participants.

Results

No major surgical complications were found in patients with EVA. Speech and language development in EVA group was comparable to that of control group.

Conclusion

$\mathrm{Cl}$ outcomes in patients with EVA regarding surgical issues, auditory benefit, and speech perception abilities are generally good.
\end{abstract}

\section{Keywords:}

cerebrospinal fluid gusher, cochlear implantation, enlarged vestibular aqueduct syndrome, speech outcome, vestibular aqueduct

Egypt J Otolaryngol 34:316-325

(C) 2018 The Egyptian Journal of Otolaryngology

$1012-5574$

\section{Introduction}

Enlarged vestibular aqueduct (EVA) is considered to be the most common radiographic abnormality apparent in temporal bone imaging of patients with congenital sensorineural hearing loss (SNHL) [1]. It could exist in isolation or be accompanied by various temporal bone abnormalities (i.e. incomplete partition) [1-7].

The overall outcome of CI in participants with EVA was generally good [1-3,5,8-20]. However, there were various concerns regarding surgical issues such as difficult or incomplete electrodes insertion that may adversely affect postoperative speech perception abilities [5], in addition to perilymphatic gushers with subsequent risk for infection such as meningitis [21]. Moreover, exact timing of $\mathrm{CI}$ in some patients with EVA is still a matter of debate owing to the fluctuating nature of hearing loss (HL) in those patients [22,23].

So, the present study aimed to investigate speech and language outcome in patients with EVA who underwent CI.

\section{Patients and methods}

This present study included 48 patients with CI. Participants were recruited from both health insurance hospitals and Alexandria University Main hospital. They were divided into two main groups according to preoperative petrous temporal bone radiological investigations. Group 1 included 24 participants who received CI with EVA. They were further subdivided according to the presence of associated anomalies into two subgroups: EVA group (group 1A), which included eight patients with isolated EVA, and EVA-IP II group (group 1B), which included 16 participants with EVA associated with other inner ear anomalies. Those anomalies were mainly IP II (modiolar hypoplasia and/or vestibular dysplasia), in addition to only one

This is an open access journal, and articles are distributed under the terms of the Creative Commons Attribution-NonCommercial-ShareAlike 4.0 License, which allows others to remix, tweak, and build upon the work non-commercially, as long as appropriate credit is given and the new creations are licensed under the identical terms. 
case with IP II associated with cochlear nerve $(\mathrm{CN})$ hypoplasia. Group 2, the control group, included 24 participants who underwent CI without any detectable radiological abnormalities of the inner ear.

All included participants were further subdivided according to the onset of $\mathrm{HL}$ in relation to language development into prelingual and perilingual participants.

An informed written consent was obtained from all participants or their parents after a detailed explanation of the study, benefits, and adverse effects. Ethical approval was obtained from ethics committee, Faculty of Medicine, Alexandria University.

Before CI, all participants were free of neuropsychiatric disorders or mental subnormality. They had severe to profound HL with minimal or no benefit from amplification and speech rehabilitation. Only patients implanted with either MED-EL (MEDEL, Innsbruck, Austria) or Advanced Bionics (AB) (Advanced Bionics Corporation, Valencia, California, USA) cochlear implants (CIs) with regular and consistent use of their devices were included in this study.

The following methodology was applied to all participants of the study.

\section{Preoperative and intraoperative data collection}

Preoperative and intraoperative data were collected from patients' records in addition to detailed history taking.

\section{Postoperative audiological assessment}

Prelingual participants must have received at least 6 months of speech rehabilitation before being assessed. Audiological assessment included the following:

(1) Meaningful auditory integration scale (MAIS): MAIS questionnaire was completed by parents after a comprehensive explanation of its items [24].

(2) Postoperative aided hearing thresholds were tested at frequencies of $250 \mathrm{~Hz}$ up to $4000 \mathrm{~Hz}$ by either play audiometry or conventional audiometry. Hearing thresholds were obtained in a soundtreated room with Madsen Itera II audiometer via a loudspeaker placed one meter behind the patient at $45^{\circ}$ to the implanted side.

(3) Aided speech reception thresholds (SRT) were tested via an audiometer built in microphone and a loudspeaker by using either Arabic spondee words, bisyllabic words, or simply by randomized Arabic digits according to participants' language development [25].

(4) Aided speech perception tests: they included Arabic speech discrimination (SD) test and speech pattern contrast test. They were presented by live voice at $40 \mathrm{~dB}$ above aided SRT or at participant's most comfortable level. Scores were calculated in percentages.

SD tests were done through two main sets of tests: closed and open sets. A downward hierarchy was constructed for testing SD. First, open-set SD tests were assumed to start with by using age-appropriate PB monosyllabic words [26]. If participant had a score greater than or equal to $60 \%$, then the test was discontinued. If score was less than this value, a closed-set test was chosen. The closed-set tests included Arabic versions of WIPI [27], ESP [28], and low verbal version of ESP tests [29].

Arabic speech pattern contrast test was applied to all patients. The original test was developed by Boothroyd [30] and was previously modified to include Arabic phonemes and words [31]. The test originally was developed to evaluate the perception of segmental and suprasegmental contrasts. It consists of two main parts: vowels and consonants perception tests. Total consonant and vowel perception scores were calculated.

Vowel perception test consists of ten items for testing vowel detection, identification, and discrimination. The main vowels $(/ \mathrm{a} /, / \mathrm{i} /, / \mathrm{o} /)$ were used. Vowels were tested first, and if total vowel perception scores were less than $50 \%$, the test was discontinued.

The original consonant perception test consists also of detection, identification, and discrimination. However, in the present study, only consonant detection and identification were tested to be suitable for all participants including young children. Consonants were presented in groups: plosives, fricatives, nasals, Arabic emphatics, and glides.

\section{Postoperative language assessment}

Arabic language test [32] was applied to all participants. Expressive (ELQ), receptive (RLQ), as well as total language (TLQ) quotients were calculated [32]. Language quotient (at certain component)=language age at this component divided by chronological age of the child.

\section{Statistical analysis of data}

SPSS data were fed to the computer and analyzed using IBM SPSS software package version 20.0. (IBM 
Corp., Armonk, New York, USA). Qualitative data were described using number and percent. Quantitative data were described using range, mean, standard deviation, and median. Significance of the obtained results was judged at the 5\% level $[33,34]$. The statistical tests used were $\chi^{2}$-test, Fisher's exact test, or Monte Carlo correction for analyzing qualitative data. Student's $t$-test, $F$-test (analysis of variance), and Kruskal-Wallis test were used for quantitative data. Pearson and Spearman coefficients were used to analyze correlations between two variables.

\section{Results and discussion \\ Preoperative data \\ Demographic data}

There was no statistical difference according to sex distribution among the three studied groups. Equal female to male ratio was found in both EVA group and control group. EVA-IP II group composed of $62.5 \%$ females and $37.5 \%$ was males. Regarding previous studies, Valvasori and Clemis found in their series that EVA accounted for $3: 2$ female to male ratio $[35,36]$. Some authors claim a slight female preponderance [4], whereas others report the reverse [17].
There was no statistical difference regarding participants' mean age in all groups. However, wider age range was observed (Fig. 1) in isolated EVA group than the other two groups. This difference arises from a significantly older age for perilingual participants of this group. This reflects that those participants could perform well with their hearing aids for longer duration before the need for CI. This may be owing to the presence of considerable aidable residual hearing in the first few years of life.

Consanguinity was present in 50, 62.5, and $83.3 \%$ of parents of participants of isolated EVA group, EVAIP II group, and control group, respectively. Moreover, $50,31.3$, and $58.3 \%$ for participants of the three groups had positive family history for HL. Generally as described in literature, EVAS is nonfamilial. However, a genetic predisposition is evident in a portion of patients affected by EVA [17,37]. Some authors suggested an autosomal recessive inheritance in participants with EVAS [17].

No apparent features for associated syndromes in both EVA and EVA-IP II groups were found in the current study. Two participants had features of Waardenburg syndrome in the control group. In literature, EVA may

\section{Figure 1}

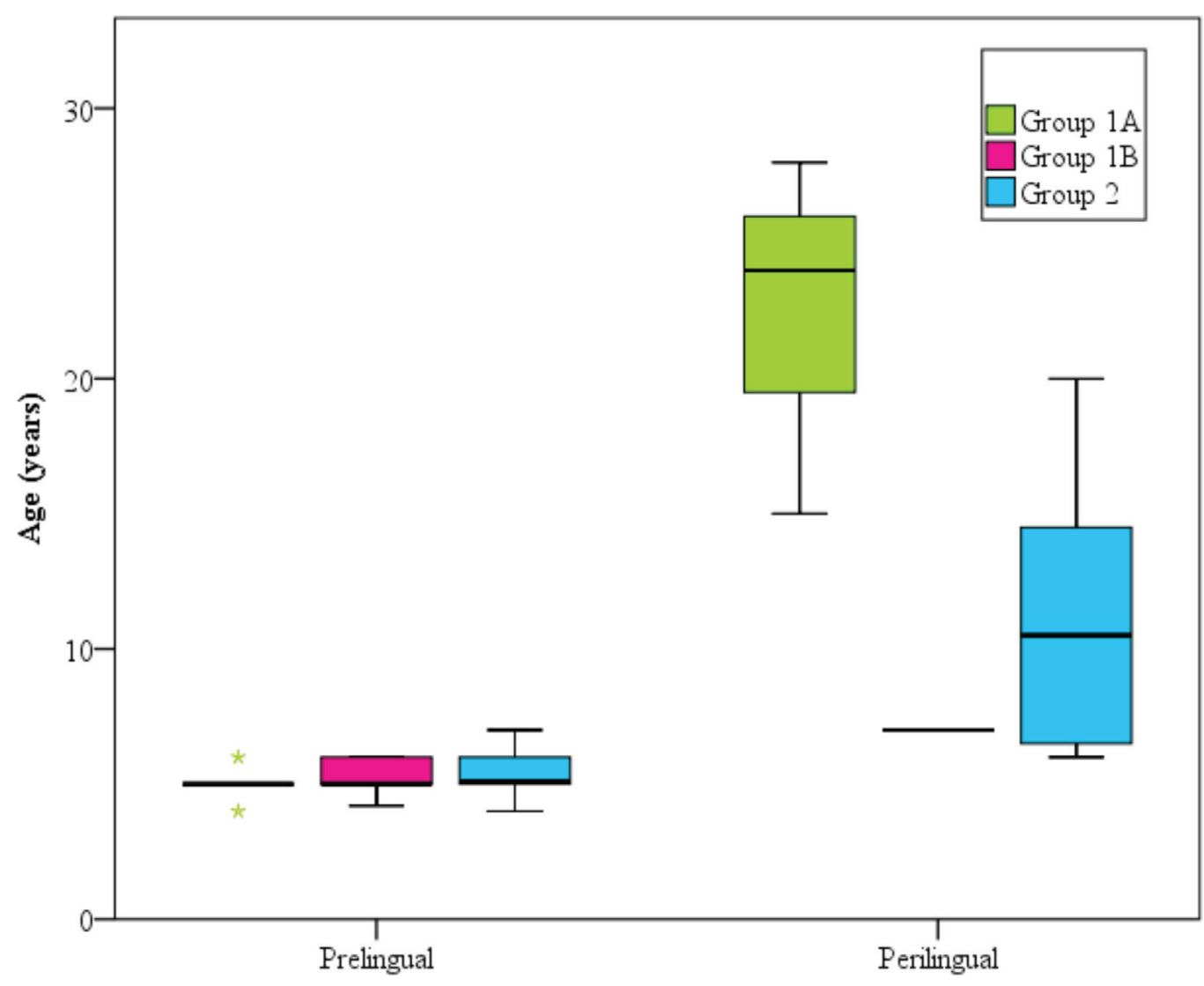

Comparison among the three studied groups according to age. 
occur as a part of several number of syndromes, mainly Pendred syndrome $[37,38]$. Other syndromes such as Waardenburg or branchio-oto-renal syndromes were documented to be associated with EVA [2].

\section{Hearing loss profile}

All participants (100\%) included in this study had SNHL. Age at HL notice ranged from 1 month to 4.0 years for both EVA and control groups and from 1 month to 2.50 years for EVA-IP II group. The course of HL was significantly different among participants of the three groups, as $50 \%$ of EVA group had stationary course, whereas the remaining $50 \%$ were either progressive or fluctuating. However, 25 and $8.3 \%$ of participants of EVA-IP II and control groups, respectively, had a progressive course, with the remaining percentages of both groups having a stationary course.

In previous studies, the audiological features of SNHL in patients with EVA have been described by many authors: SNHL may be mild to profound, and patients with EVA without hearing impairment have also been reported. In a variable percentage of cases, it has been described to be fluctuant and progressive $[2,17,39]$.

Duration of amplification before CI did not differ significantly between the studied groups. However, it was of wide range (0.5-25 years) for isolated EVA group. This may be because of the variability of course and degree at initial diagnosis among those participants.

Regarding preoperative aided hearing thresholds, there was no statistical significant difference between groups except for at test frequencies of 2000 and $3000 \mathrm{~Hz}$. EVA group had significantly better thresholds at these frequencies.

Table 1 shows the percentage of associated vestibular manifestations in both EVA and EVA IP II. The percentage for associated vestibular symptoms was higher in EVA patients (37.5\%) as compared with the control group. One of those participants was aged four years and was manifested by slight but consistent imbalance, observed by his mother, which sometimes was associated with vomiting. This occurred mainly on waking up. These manifestations were present before $\mathrm{CI}$ and also persisted postoperatively. The other two participants were older enough to describe their manifestations on their own. One of them described true vertiginous attacks associated with vomiting. The other patient described less specific attacks of dizziness.
Table 1 Comparison among the three studied groups according to associated vestibular symptoms

\begin{tabular}{|c|c|c|c|c|c|}
\hline & $\begin{array}{c}\text { EVA } \\
\text { group } \\
(n=8)[n \\
(\%)]\end{array}$ & $\begin{array}{l}\text { EVA-IP II } \\
\text { group } \\
(n=16)[n \\
(\%)]\end{array}$ & $\begin{array}{c}\text { Control } \\
\text { group } \\
(n=24)[n \\
(\%)]\end{array}$ & $\chi^{2}$ & ${ }^{\mathrm{MC}} P$ \\
\hline $\begin{array}{l}\text { Vestibular } \\
\text { manifestation }\end{array}$ & $3(37.5)$ & $1(6.3)$ & $0(0.0)$ & $8.071^{*}$ & $0.005^{\star}$ \\
\hline $\begin{array}{l}\text { Significance } \\
\text { between } \\
\text { groups }\end{array}$ & \multicolumn{5}{|c|}{${ }^{\mathrm{FE}} P_{1}=0.091,{ }^{\mathrm{FE}} P_{2}=0.011^{*},{ }^{\mathrm{FE}} P_{3}=0.400$} \\
\hline \multicolumn{6}{|c|}{$\begin{array}{l}\chi^{2}, \chi^{2} \text {-test for comparing among the three groups and each two } \\
\text { groups; EVA, enlarged vestibular aqueduct; }{ }^{\mathrm{FE}} P, P \text { value for } \\
\text { Fisher exact test for chi-square test for comparing between the } \\
\text { two groups; }{ }^{\mathrm{MC}} P, P \text { value for Monte Carlo for } \chi^{2} \text { test for comparing } \\
\text { between the three groups; } P_{1}, P \text { value for comparing between } \\
\text { EVA group and EVA-IP II group; } P_{2}, P \text { value for comparing } \\
\text { between EVA group and control group; } P_{3}, P \text { value for comparing } \\
\text { between EVA-IP II group and control group. } P \leq 0.05 \text {, statistically } \\
\text { significant. }\end{array}$} \\
\hline
\end{tabular}

In IP II-EVA group, there was only one case but with interesting findings. A 7-year-old male diagnosed as IP II. His mother documented frequent attacks of vomiting associated by vertigo since an early age. After the operations, attacks persisted. Moreover, he developed a significant drop attack. The vertigo was unrelated to electrical stimulation of his implant. No vestibular manifestations were encountered in the control group.

There are few published descriptions of vestibular manifestations and objective vestibular test results in patients with EVA. In previous study, vestibular symptoms in patients with EVA ranged from severe episodic vertigo to occasional unsteadiness in adults, whereas delayed walking owing to incoordination and imbalance was reported to predominate in children [17]. Other studies assumed that vestibular hypofunction seems to be more common [7]. The reported percentages of patients with EVA with vestibular signs and symptoms vary from 0 to $100 \%$ $[2,4,40,41]$. However, in the present study, the prevalence of vestibular manifestations in all groups may be underestimated as most cases were from pediatric population.

\section{Preoperative radiological findings}

Dimensions of vestibular aqueduct were measured on $\mathrm{CT}$ at both the operculum and its mid portion. No significant differences were found in dimensions of vestibular aqueduct in both subgroups as shown in Table 2.

In the current study, correlations made between dimensions of VA and both degree of HL at initial diagnosis and vestibular manifestations were insignificant. Some previous studies generally 
Table 2 Radiological dimensions of VA in both EVA and EVA-IP II groups

\begin{tabular}{|c|c|c|c|c|}
\hline Radiological dimensions of VA & EVA group $(n=8)[n(\%)]$ & EVA-IP II group $(n=16)[n(\%)]$ & Test of significance & $P$ \\
\hline \multicolumn{5}{|c|}{ Dimensions of VA at operculum (mm) } \\
\hline Minimum-maximum & $3.0-7.0$ & $2.50-6.0$ & $t=1.831$ & 0.081 \\
\hline Mean \pm SD & $4.73 \pm 1.36$ & $3.86 \pm 0.93$ & & \\
\hline Median & 4.90 & 3.75 & & \\
\hline \multicolumn{5}{|l|}{ VA dimensions at midpoint $(\mathrm{mm})$} \\
\hline Minimum-maximum & $1.60-3.0$ & $2.0-3.50$ & $t=1.113$ & 0.278 \\
\hline Mean \pm SD & $2.41 \pm 0.48$ & $2.66 \pm 0.52$ & & \\
\hline Median & 2.50 & 2.65 & & \\
\hline
\end{tabular}

EVA, enlarged vestibular aqueduct; $t, P: t$ and $P$ values for Student's $t$-test for comparing between the two groups. ${ }^{*} P \leq 0.05$, statistically significant.

assumed positive correlations between dimensions of VA and degree of HL [1,2]. However, a strict correlation between the size of the VA and the degree of HL has not been established [2,17]. A previous study investigated the correlation between VA dimensions and the severity of vestibular manifestations. However, no significant correlations were made [41].

\section{Intraoperative data}

Surgical procedure was through a postauricular incision, with classical mastoidectomy via posterior tympanotomy approach with round widow or less commonly cochleostomy approaches. All participants of the three studied groups were implanted on the right side except for one participant in EVA-IP II group that has implanted on the left side after failed right insertion.

Table 3 demonstrates the documented intraoperative complications. They were not significantly different among the three groups except for cerebrospinal fluid (CSF) gusher, which accounted for $37.5 \%$ for both EVA and EVA-IP II groups. However, it was easily controlled by fascia packing. No gusher was documented in control group.

The incidence rate of CSF gushers in CI patients with EVA according to previous studies was extremely variable $[20,21,42]$. However, all studies agreed that in such cases, it was easily controlled by sealing it with a fragment of temporal muscle fascia $[2,20,21]$. Moreover, in the present study, no correlations were found between the occurrence of intraoperative CSF gusher and VA dimensions. This was in accordance with Vassoler et al. [15].

Traumatic facial nerve injury was documented intraoperatively in only one case in EVA-IP II group. It is well documented from previous studies that IP- type II may be associated with abnormal course of facial nerve [43-45].
Table 3 Comparison according to intraoperative complications in the three groups

\begin{tabular}{|c|c|c|c|c|c|}
\hline $\begin{array}{l}\text { Intraoperative } \\
\text { complications }\end{array}$ & $\begin{array}{c}\text { Group } \\
1 \mathrm{~A} \\
(n=8)[n \\
(\%)]\end{array}$ & $\begin{array}{c}\text { Group } \\
1 \mathrm{~B} \\
(n=16) \\
{[n(\%)]} \\
\end{array}$ & $\begin{array}{c}\text { Group } 2 \\
(n=24) \\
{[n(\%)]}\end{array}$ & $x^{2}$ & ${ }^{\mathrm{MC}} P$ \\
\hline $\begin{array}{l}\text { Incomplete } \\
\text { electrodes } \\
\text { insertion }\end{array}$ & $1(12.5)$ & $4(25.0)$ & 7 (29.2) & 0.766 & 0.749 \\
\hline Gusher & $3(37.5)$ & $6(37.5)$ & $0(0.0)$ & $12.382^{*}$ & $0.002^{*}$ \\
\hline $\begin{array}{l}\text { Failure of } \\
\text { insertion }\end{array}$ & $0(0.0)$ & $1(6.3)$ & $1(4.2)$ & 0.762 & 1.000 \\
\hline $\begin{array}{l}\text { Facial nerve } \\
\text { injury }\end{array}$ & $0(0.0)$ & $1(6.3)$ & $0(0.0)$ & 2.147 & 0.495 \\
\hline
\end{tabular}

Intraoperative electrodes impedance

Mean intraoperative impedance for each electrode was compared between the three studied groups. There was no statistical difference between groups.

\section{Postoperative data}

Programming data

For MEDEL CI, all participants of both EVA and control groups in addition to $85.7 \%$ of EVA IP II group used FS4 strategy, which is the default one recommended by the manufacturer. FS4p strategy was applied to two patients from control group after giving unsatisfactory results with the default strategy. For $\mathrm{AB} C \mathrm{CI}$, all participants in the three groups used Hires Optima-S strategy as a default.

Mean most comfortable level (MCL) for apical, middle, and basal electrodes was compared between different groups for participants with MED-EL CIs. Mean MCLs for EVA group for the three electrode regions were observed to be lower than the other two groups. However, this was statistically significant only in mean MCL for middle electrodes where the difference was between EVA and EVA-IP II groups (Fig. 2). By comparing the three electrode regions, apical electrodes had the lowest mean MCL levels than both middle and basal electrodes in the three studied group. 


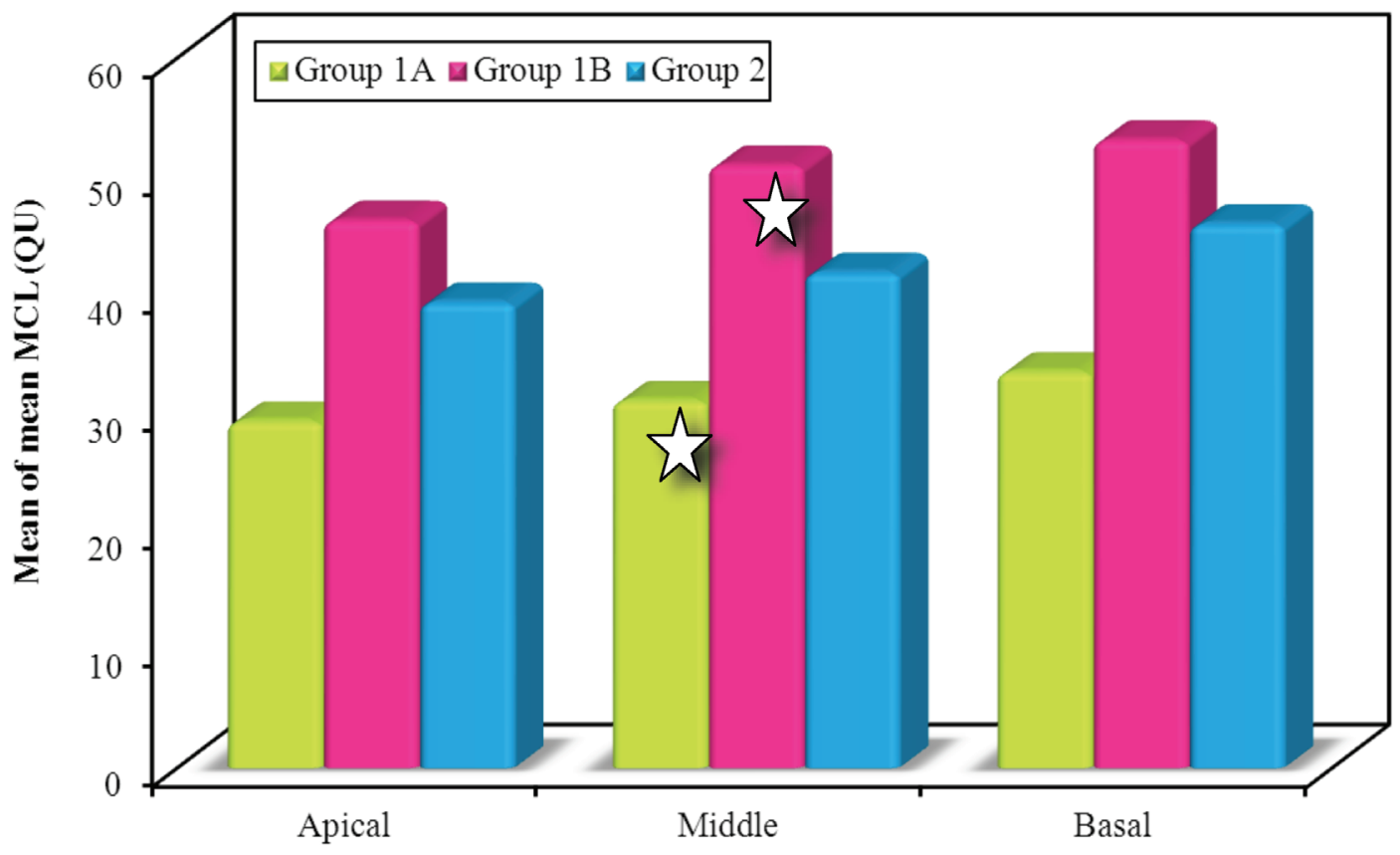

Mean MCL for the electrode regions in the three groups.

Table 4 Meaningful auditory integration scale questionnaire total scores comparison between the three groups

\begin{tabular}{|c|c|c|c|c|c|}
\hline MAIS questionnaire & Group $1 \mathrm{~A}(n=8)$ & Group 1B $(n=16)$ & Group $2(n=24)$ & $H$ & $P$ \\
\hline \multicolumn{6}{|l|}{ Total score } \\
\hline Minimum-maximum & $27.0-35.0$ & $12.0-37.0$ & $28.0-37.0$ & $9.429^{*}$ & $0.009^{*}$ \\
\hline Mean \pm SD & $33.63 \pm 2.77$ & $29.63 \pm 5.74$ & $33.33 \pm 2.50$ & & \\
\hline Median & 35.0 & 31.0 & 34.0 & & \\
\hline Significance between the groups & \multicolumn{5}{|c|}{$P_{1}=0.012^{*}, P_{2}=0.591, P_{3}=0.007^{*}$} \\
\hline
\end{tabular}

$H, P: H$ and $P$ values for Kruskal-Wallis test; significance between each two groups was done using post-hoc test (Dunn's multiple comparisons test); MAIS, meaningful auditory integration scale; $P_{1}, P$ value for comparing between group $1 \mathrm{~A}$ and group $1 \mathrm{~B} ; P_{2}, P$ value for comparing between group $1 \mathrm{~A}$ and group $2 ; P_{3}, P$ value for comparing between group $1 \mathrm{~B}$ and group 2 . ${ }^{*} P \leq 0.05$, statistically significant.

\section{Audiological, speech, and language assessment}

Mean total score of MAIS questionnaire (Table 4) was significantly lower in EVA-IP II group than both EVA and control groups. MAIS questionnaire gathers auditory behavioral information to evaluate a child's skills in meaningful and real-world situation.

Postoperative aided hearing thresholds did not show significant differences between the three studied groups except at test frequency of $4000 \mathrm{~Hz}$ where EVA-IP II patients had significantly higher thresholds than control group (Fig. 3). No statistical difference in the mean thresholds was recorded among the three studied groups regarding aided SRT.

The mean duration of speech rehabilitation before speech perception testing was around one year in the three groups. Speech perception test results of EVA group were comparable to the control group. Both groups yielded better outcome than EVA-IPII group after the same duration of appropriate speech rehabilitation.

Figure 4 demonstrates percentage of participants that passed open set of aided SD tests according to 'pass/ failed' criteria established for each test. EVA and control groups had comparable percentages of participants who passed those tests. Meanwhile, EVA-IP II group had significantly lower percentage. Moreover, $25 \%$ of that group did not pass the closed set tests.

Regarding the mean scores of open-set SD tests (Table 5), isolated EVA patients had markedly higher mean score as compared with the other two groups. More comprehensively, this marked difference arises from the perilingual patients of the three studied groups. Regarding the prelingual patients, marked higher mean score for EVA group was present. However, it did not reach the statistical significance. This may be owing to the very small sample size $(n=3)$. 
Figure 3

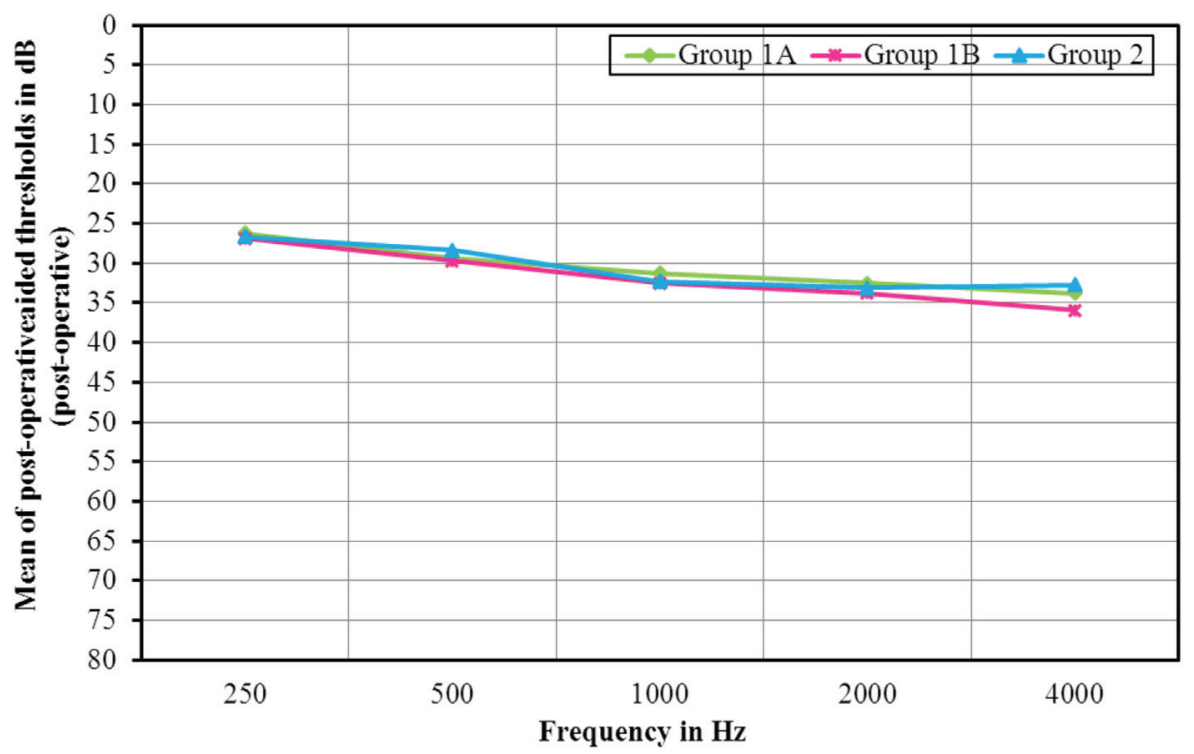

Aided hearing thresholds for the three studied groups.

\section{Figure 4}

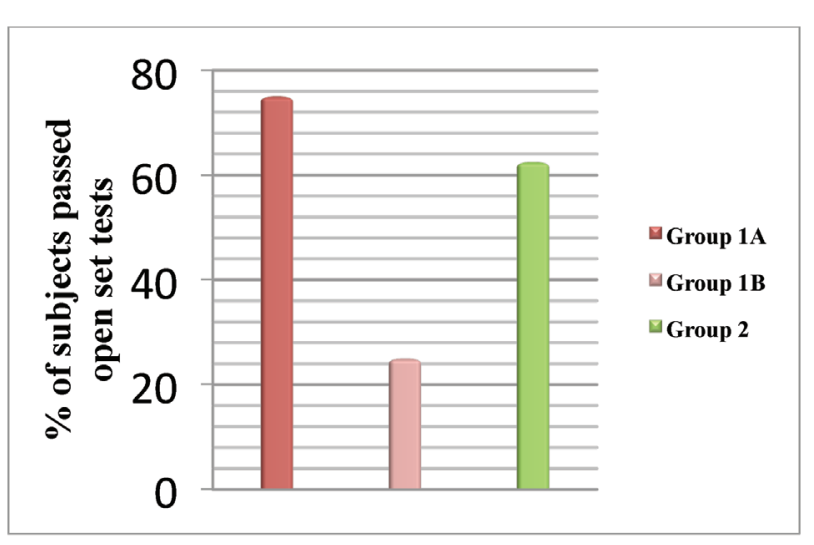

Percentage of subjects that passed open-set-aided speech discrimination tests in the three groups.

Significant negative correlations were found between open set-aided SD test scores with preoperative aided hearing thresholds in EVA-IP II group at frequencies of $250,500,3000$, and $4000 \mathrm{~Hz}$. Although negative trend for correlations in both EVA and control groups was observed, they did not reach the level of statistical significance (Table 6).

Total vowel perception test scores in prelingual EVA subjects (Table 7) were significantly higher than EVAIP II group. Although total consonants identification mean scores were noticeably higher for EVA group than the other two groups, this difference didn't reach statistical significance. Total vowel and consonants perception test scores were correlated to preoperative aided hearing thresholds. As regards to these correlations, significant negative correlations (Fig. 5) were found in EVA group for 250, 500, 1000, and $2000 \mathrm{~Hz}$. Whereas, a negative correlation was found between consonants perception test scores and preoperative aided hearing threshold at only $2000 \mathrm{~Hz}$ in the same group.

Regarding postoperative LQ, it was observed that LQs for almost all tested language components for isolated EVA were higher than the other two groups. Prelingual patients of EVA group had a significantly higher ELQ than that of EVA-IP II group. For perilingual patients, ELQ was significantly higher than that of control group. TLQ for EVA patients was markedly higher (although not statistically significant; $P=0.052 / 0.057)$ than the other two groups (Table 8 ).

In the earlier studies by Bent et al. [19] and Harker et al. [20], children with EVA showed excellent results in speech perception tests. These results were attributed to postlingual nature of $\mathrm{HL}$ in those children. Bent et al. [19] also concluded that those children were actually better CI candidates than children with congenital HL. Similar results were obtained by Vassoler et al. [15]. On the contrary, Lee et al. [11] found variability in SD scores in children with EVA after receiving CI. However, participants in their study were heterogeneous regarding associated inner ear malformations.

Another study by Buchman et al. [46] revealed that children with IP-EVA spectrum abnormalities frequently achieve good performance, with $100 \%$ of 
Table 5 Comparison between groups according to open-set speech discrimination test scores (\%)

\begin{tabular}{|c|c|c|c|c|c|}
\hline & EVA group & EVA-IP II group & Control group & $F$ & $P$ \\
\hline \multicolumn{6}{|l|}{ Prelingual } \\
\hline Open set test & $n=3$ & $n=2$ & $n=9$ & & \\
\hline Minimum-maximum & $84.0-88.0$ & $64.0-84.0$ & $64.0-92.0$ & 0.947 & 0.418 \\
\hline Mean \pm SD & $86.67 \pm 2.31$ & $74.0 \pm 14.14$ & $77.33 \pm 12.49$ & & \\
\hline Median & 88.0 & 74.0 & 72.0 & & \\
\hline \multicolumn{6}{|l|}{ Perilingual } \\
\hline Open set test & $n=3$ & $n=2$ & $n=6$ & & \\
\hline Minimum-maximum & $81.0-90.0$ & $80.0-84.0$ & $64.0-84.0$ & $4.941^{*}$ & $0.040^{*}$ \\
\hline Mean \pm SD & $85.33 \pm 4.51$ & $82.0 \pm 2.83$ & $73.33 \pm 6.53$ & & \\
\hline Median & 85.0 & 82.0 & 72.0 & & \\
\hline Significance between the groups & \multicolumn{4}{|c|}{$P_{1}=0.804, P_{2}=0.043^{*}, P_{3}=0.213$} & \\
\hline
\end{tabular}

EVA, enlarged vestibular aqueduct; $F, P: F$ and $P$ values for analysis of variance test.

Table 6 Correlation between open-set speech discrimination test scores and preoperative aided thresholds in each group

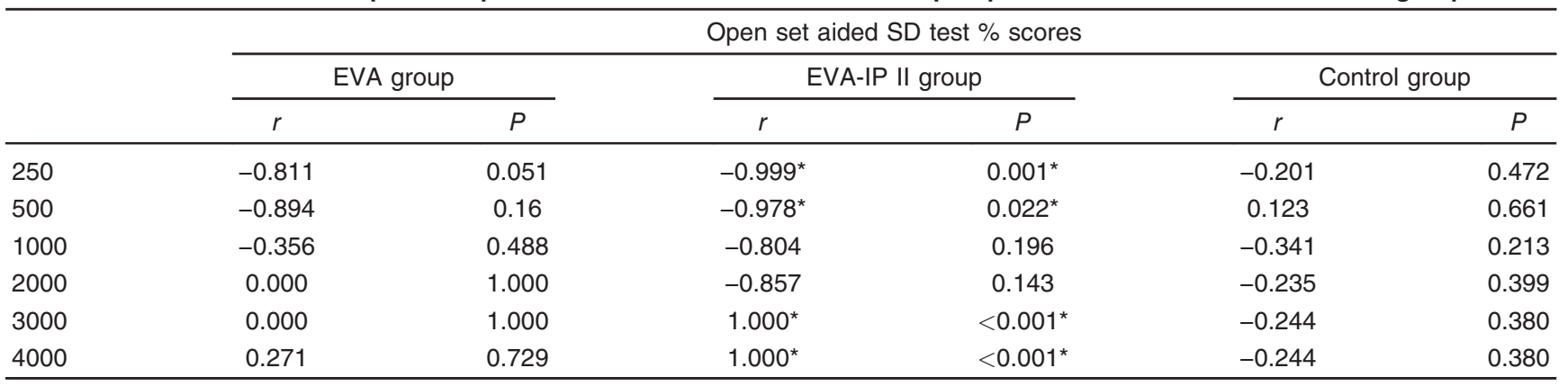

EVA, enlarged vestibular aqueduct; $r$, Pearson's coefficient; SD, speech discrimination. ${ }^{\star} P \leq 0.05$, statistically significant.

Figure 5
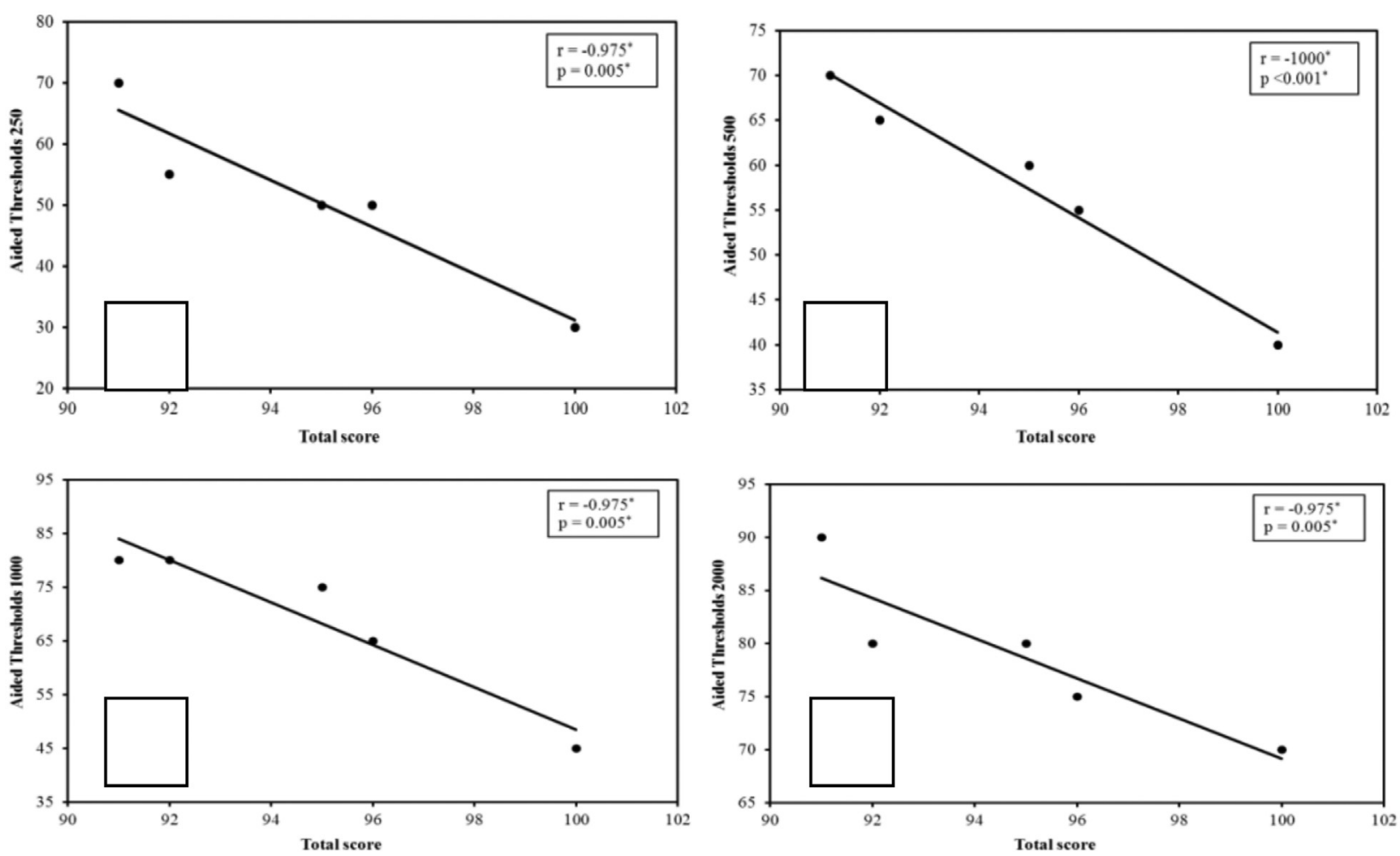

Correlation between total vowel identification test scores and preoperative hearing aided thresholds in prelingual subjects of enlarged vestibular aqueduct group at (a) $250 \mathrm{~Hz}$, (b) $500 \mathrm{~Hz}$, (c) $1000 \mathrm{~Hz}$, and (d) $2000 \mathrm{~Hz}$. 
Table 7 Vowel perception test scores among the prelingual subjects of the three groups

\begin{tabular}{|c|c|c|c|c|c|}
\hline Total vowel score & EVA group & EVA-IP-II group & Control group & $H$ & $P$ \\
\hline Prelingual subjects & $\mathrm{n}=5$ & $n=13$ & $n=16$ & & \\
\hline Minimum-maximum & $91.0-100.0$ & $33.0-97.0$ & $58.0-100.0$ & $7.640^{*}$ & $0.022^{*}$ \\
\hline Mean \pm SD & $94.80 \pm 3.56$ & $71.38 \pm 22.87$ & $89.42 \pm 13.90$ & & \\
\hline Median & 95.0 & 74.0 & 96.0 & & \\
\hline Significance between groups & \multicolumn{4}{|c|}{$P_{1}=0.042^{*}, P_{2}=0.795, P_{3}=0.012^{*}$} & \\
\hline
\end{tabular}

EVA, enlarged vestibular aqueduct; $H, P: H$ and $P$ values for Kruskal-Wallis test; significance between each two groups was done using post-hoc test (Dunn's multiple comparisons test); $P_{1}, P$ value for comparing between group 1A and group 1B; $P_{2}, P$ value for comparing between group $1 \mathrm{~A}$ and group $2 ; P_{3}, P$ value for comparing between group $1 \mathrm{~B}$ and group $2 .{ }^{*} P \leq 0.05$, statistically significant.

Table 8 Comparison according to expressive language quotient and total language quotient in the three studied groups

\begin{tabular}{|c|c|c|c|c|c|}
\hline & EVA group & EVA-IP II group & Control group & $H$ & $P$ \\
\hline \multicolumn{6}{|l|}{ ELQ } \\
\hline Prelingual & $n=5$ & $n=13$ & $n=16$ & & \\
\hline Minimum-maximum & $41.0-75.0$ & $30.0-50.0$ & $33.0-90.0$ & $6.137^{*}$ & $0.046^{*}$ \\
\hline Mean \pm SD & $64.20 \pm 14.34$ & $41.15 \pm 7.31$ & $54.35 \pm 20.44$ & & \\
\hline Median & 70.0 & 42.0 & 46.0 & & \\
\hline Significance between groups & \multicolumn{3}{|c|}{$P_{1}=0.018^{*}, P_{2}=0.210, P_{3}=0.107$} & & \\
\hline Perilingual & $n=3$ & $n=3$ & $n=8$ & & \\
\hline Minimum-maximum & $100.0-100.0$ & $50.0-86.0$ & $30.0-100.0$ & $6.052^{*}$ & $0.048^{*}$ \\
\hline Mean \pm SD & $100.0 \pm 0.0$ & $69.0 \pm 18.08$ & $57.75 \pm 22.66$ & & \\
\hline Median & 100.0 & 71.0 & 58.50 & & \\
\hline Significance between groups & & $38, P_{2}=0.014^{*}, P$ & & & \\
\hline \multicolumn{6}{|l|}{ TLQ } \\
\hline Prelingual & $n=5$ & $n=13$ & $n=16$ & & \\
\hline Minimum-maximum & $33.0-90.0$ & $30.0-60.0$ & $33.0-100.0$ & 5.985 & 0.052 \\
\hline Mean \pm SD & $68.60 \pm 21.27$ & $42.69 \pm 8.97$ & $58.31 \pm 22.83$ & & \\
\hline Median & 75.0 & 42.0 & 50.0 & & \\
\hline Perilingual & $n=3$ & $n=3$ & $n=8$ & & \\
\hline Minimum-maximum & $100.0-100.0$ & $57.0-71.0$ & $40.0-100.0$ & 5.722 & 0.057 \\
\hline Mean \pm SD & $100.0 \pm 0.0$ & $66.33 \pm 8.08$ & $66.25 \pm 19.41$ & & \\
\hline Median & 100.0 & 71.0 & 70.0 & & \\
\hline
\end{tabular}

ELQ, expressive language quotient; EVA, enlarged vestibular aqueduct; $H, P: H$ and $P$ values for Kruskal-Wallis test; significance between each two groups was done using post-hoc test (Dunn's multiple comparisons test); $P_{1}, P$ value for comparing between EVA group and EVA-IP II group; $P_{2}, P$ value for comparing between EVA group and control group; $P_{3}, P$ value for comparing between EVA-IP II group and control group; TLQ, total language quotient. * $P \leq 0.05$, statistically significant.

these developing open-set speech perception skills (>20 month use). They, however, did not mention speech perception results in patients with isolated EVA separately. On the contrary, they documented that children with hypoplastic malformations or $\mathrm{CN}$ deficiency have achieved open-set test speech perception abilities much less frequently (50 and 19\%, respectively) [46].

In the present study, there was one case of EVA-IP II associated with bilateral $\mathrm{CN}$ hypoplasia. She was tested after $\sim 20$ months of regular speech rehabilitation. However, she did not pass the lowest level for SD tests. She had a score of $50 \%$ in pattern perception category of low verbal ESP test (category 1). However, she had a score of $60 \%$ in MAIS questionnaire together with aided hearing thresholds that were comparable to other participants in EVA IP II group.

\section{Conclusion}

Participants with EVA have a good outcome regarding surgical issues, auditory benefit as well as speech and language development. All these make those participants excellent candidates for CI.

\section{Financial support and sponsorship}

Nil.

\section{Conflicts of interest}

There are no conflicts of interest.

\section{References}

1 Madden C, Halsted M, Benton C, Greinwald J, Choo D. Enlarged vestibular aqueduct syndrome in the pediatric population. Otol Neurotol 2003; 24:625-632.

2 Gopen Q, Zhou G, Whittemore K, Kenna M. Enlarged vestibular aqueduct: review of controversial aspects. Laryngoscope 2011; 121:1971-1978. 
3 Varghese CM, Scampion P, Das VK, Gillespie J, Umapathy D. Enlarged vestibular aqueduct in two male siblings. Dev Med Child Neurol 2002; 44:706-711.

4 Walsh RM, Ayshford CA, Chavda SV, Proops DW. Large vestibular aqueduct syndrome. ORL J Otorhinolaryngol Relat Spec 1999; 61:41-44.

5 Au G, Gibson W. Cochlear implantation in children with large vestibular aqueduct syndrome. Am J Otol 1999; 20:183-186.

6 Zalzal GH, Tomaski SM, Vezina LG, Bjornsti P, Grundfast KM. Enlarged vestibular aqueduct and sensorineural hearing loss in childhood. Arch Otolaryngol Head Neck Surg 1995; 121:23-28.

7 Jackler RK, De La Cruz A. The large vestibular aqueduct syndrome. Laryngoscope 1989; 99:1238-1242. Discussion 42-43.

8 Pritchett C, Zwolan T, Huq F, Phillips A, Parmar H, Ibrahim M, et al. Variations in the cochlear implant experience in children with enlarged vestibular aqueduct. Laryngoscope 2015; 125:2169-2174.

9 Tse KS, Chu KM, Chiu LF, Fan TW, Tsang T, Kwan TL. Congenital inner ear malformations. Hong Kong J Radiol 2011; 14:118-125.

10 Chen X, Liu B, Liu S, Mo L, Liu H. The development of auditory skills in infants with isolated large vestibular aqueduct syndrome after cochlear implantation. Int J Pediatr Otorhinolaryngol 2011; 75:943-947.

11 Lee KH, Lee J, Isaacson B, Kutz JW, Roland PS. Cochlear implantation in children with enlarged vestibular aqueduct. Laryngoscope 2010; 120:1675-1681.

12 Sennaroglu L. Cochlear implantation in inner ear malformations-a review article. Cochlear Implants Int 2009; 11:4-41.

13 Dewan K, Wippold FJ2nd, Lieu JE. Enlarged vestibular aqueduct in pediatric sensorineural hearing loss. Otolaryngol Head Neck Surg 2009; 140:552-558.

$14 \mathrm{Wu}$ CM, Sun YS, Liu TC. Long-term speech perception of cochlear implantation in children with large vestibular aqueduct syndrome: how we do it. Clin Otolaryngol 2008; 33:472-475.

15 Vassoler TM, Bergonse Gda F, Meira Junior S, Bevilacqua MC, Costa Filho $\mathrm{OA}$. Cochlear implant and large vestibular aqueduct syndrome in children. Braz J Otorhinolaryngol 2008; 74:260-264.

16 Incesulu A, Adapinar B, Kecik C. Cochlear implantation in cases with incomplete partition type III (X-linked anomaly). Eur Arch Otorhinolaryngol 2008; 265:1425-1430.

17 Berrettini S, Forli F, Bogazzi F, Neri E, Salvatori L, Casani AP, et al. Large vestibular aqueduct syndrome: audiological, radiological, clinical, and genetic features. Am J Otolaryngol 2005; 26:363-371.

18 Nowak $\mathrm{KC}$, Messner $\mathrm{AH}$. Isolated large vestibular aqueduct syndrome in a family. Ann Otol Rhinol Laryngol 2000; 109:40-44.

19 Bent JP3rd, Chute P, Parisier SC. Cochlear implantation in children with enlarged vestibular aqueducts. Laryngoscope 1999; 109(Pt 1):1019-1022.

20 Harker LA, Vanderheiden S, Veazey D, Gentile N, McCleary E. Multichannel cochlear implantation in children with large vestibula aqueduct syndrome. Ann Otol Rhinol Laryngol Suppl 1999; 177:39-43.

21 Bianchin G, Polizzi V, Formigoni P, Russo C, Tribi L. Cerebrospinal fluid leak in cochlear implantation: enlarged cochlear versus enlarged vestibular aqueduct (common cavity excluded). Int J Otolaryngol 2016; 2016:6591684.

22 Ko HC, Liu TC, Lee LA, Chao WC, Tsou YT, Ng SH, et al. Timing of surgical intervention with cochlear implant in patients with large vestibular aqueduct syndrome. PLoS One 2013; 8:e81568.

23 Hazmi M, Ab Aziz A, Asma A. Familial pattern of large vestibular aqueduct syndrome in a Chinese family. Excli J 2013; 12:118-121.

24 M Robbins A, J Renshaw J, W Berry S. Meaningful Auditory Integration Scale. Evaluating meaningful auditory integration in profoundly deaf children; 1991. pp. 144-150.
25 Soliman S, El-Mahallawy T. Simple speech test material as a predictor for speech reception threshold in preschool children. Cairo: Ain Shams university; 1984.

26 Soliman S. speech discrimination audiometry using Arabic phonetically balanced words. Ain shams Med J 1976; 27:27-30.

27 Soliman S, Abd El-Hady M, Saad M, Kolkaila E. Development and study of Arabic word intelligibility by picture identification (WIPI) in normal hearing Egyptian children. Sci J Al-Azhar Univ Med Fac Girls 1987; 5:6.

28 El Kholi W. Development of an Arabic pediatric speech perception test battery. Egypt J Otolaryngol 2001; 18:1-16

29 El Danasoury I, El Kholi W, Morgan A. The Arabic low verbal early speech perception test: development and application. Sci J Al-Azhar Med Fac 2006; 27:1187-1201.

30 Boothroyd A. Auditory perception of speech by subjects with sensorineural hearing loss. J Speech Hear Res 1984; 27:134-144.

31 Talaat M. Electrical and speech outcome measures for the evaluation of cochlear implantees. Alexandria: University of Alexandria; 2009

32 Kotby M, Khairy A, Barakah M, Rifaie N, Elshobary A. Language testing of Arabic speaking children. Proceedings of the XXIII World Congress of the International Association of Logopedics and Phoniatrics. 1995; Cairo.

33 Kirkpatrick LA, Feeney BC. A simple guide to IBM SPSS statistics for version 20.0. Student ed. Belmont: Wadsworth, Cengage Learning 2013.

34 Kotz S, Balakrishnan N, Read CB, Vidakovic B. Encyclopedia of statistical sciences. 2nd ed., Hoboken: Wiley-Interscience 2006.

35 Valvassori GE, Clemis JD. The large vestibular aqueduct syndrome. Laryngoscope 1978; 88:723-728.

36 Valvassori GE, Clemis JD. Abnormal vestibular aqueduct in cochleovestibular disorders. Adv Otorhinolaryngol 1978; 24:100-105.

37 Pryor SP, Madeo AC, Reynolds JC. SLC26A /PDS genotype-phenotype correlation in hearing loss with enlargement of the vestibular aqueduct (EVA): evidence that Pendred syndrome and non-syndromic EVA are distinct clinical and genetic entities. J Med Genet 2005; 42:159-165.

38 Campbell C, Cucci RA, Prasad S, Green GE, Edeal JB, Galer CE, et al. Pendred syndrome, DFNB4, and PDS/SLC26A4 identification of eight novel mutations and possible genotype-phenotype correlations. Hum Mutat 2001; 17:403-411.

39 Rah YC, Kim AR, Koo JW, Lee JH, Oh SH, Choi BY. Audiologic presentation of enlargement of the vestibular aqueduct according to the SLC26A4 genotypes. Laryngoscope 2015; 125:E216-E222.

40 Zhou G, Gopen Q. Characteristics of vestibular evoked myogenic potentials in children with enlarged vestibular aqueduct. Laryngoscope 2011; 121:220-225

41 Yang CJ, Lavender V, Meinzen-Derr JK, Cohen AP, Youssif M, Castiglione $\mathrm{M}$, et al. Vestibular pathology in children with enlarged vestibular aqueduct. Laryngoscope 2016; 126:2344-2350.

42 Pradhananga R, Natarajan K, Devarasetty A, Kameswaran M. Cochlear Implantation in Isolated Large Vestibular Aqueduct Syndrome: Report of Three Cases and Literature Review. Int Arch Otorhinolaryngol 2015; 19:359-363.

43 Takhellambam BS, Venkataramani N, Natarajan K, Kumari A. Cochlea implant in patients with incomplete partition type II: surgical considerations. Int J Otorhinolaryngol Head Neck Surg 2017; 3:1081-1086.

44 Berrettini S, Forli F, De Vito A, Bruschini L, Quaranta N. Cochlear implant in incomplete partition type I. Acta Otorhinolaryngol Ital 2013; 33:56-62.

45 Slattery WH3rd, Luxford WM. Cochlear implantation in the congenital malformed cochlea. Laryngoscope 1995; 105:1184-1187.

46 Buchman CA, Teagle HF, Roush PA, Park LR, Hatch D, Woodard J, et al. Cochlear implantation in children with labyrinthine anomalies and cochlear nerve deficiency: implications for auditory brainstem implantation. Laryngoscope 2011; 121:1979-1988. 